\title{
Carer needs on an organic inpatient unit
}

Clegg, J. \& Craven-Staines, S.

Email: Jennifer.clegg1@nhs.net

Email: s.craven-staines@tees.ac.uk

Address:

Doctorate in Clinical Psychology

School of Social Sciences Humanities and Law

Teesside University

Middlesbrough

TS1 3BX

\begin{abstract}
Purpose

The purpose of the research is to further understand the needs of carers when a relative with dementia is admitted to an organic impatient ward.
\end{abstract}

Design

A constructivist grounded theory approach was employed to generate a substantive theory to understand the needs of carers and how staff perceive carer needs when a relative is admitted to a dementia ward. Five relatives and six members of staff were interviewed using purposive and theoretical sampling. Interview transcripts were analysed using initial, focused and theoretical coding using constant comparative methods to develop the end theory.

\section{Findings}

The grounded theory concluded that carers have three categories of needs: 'The Safe and Cared for Relative', 'The Informed Carer and 'The Understanding, Responsive and Available Service'. Underpinning the needs are the relationships between carers, their relative and staff. Three barriers were identified which can impact on these needs being effectively met. These identified barriers were: Loss, Time and Ineffective Communication.

\section{Originality}

The grounded theory demonstrates that carers needs fundamentally relate to their relatives being safe and cared for and being included and informed during the admission. Relationships can be ruptured when a barrier prevents the needs from being effectively met. Recommendations are made to aim to reduce the impact of the barriers and to aid staff in developing their understanding of the carer experience. 


\section{Introduction}

Dementia is a clinical term relating to a group of neurodegenerative diseases. Each disease shares characteristics of progressive deficits in behaviour, executive function and language (Bang, Spina \& Miller, 2015). In the United Kingdom (UK), Alzheimer's disease is the most common form of dementia, accounting for two thirds of all cases. This is followed by Vascular Dementia, Lewy Bodies Dementia and Frontal Temporal Lobe Dementia (Prince, Wimo, Guerchet, Ali, et al., 2015). In 2014, it was estimated there were 850,000 living with dementia in the UK, expecting to reach 2 million by 2051 (Prince, Knapp, Guerchet, McCrone, et al., 2014).

The care needs of individuals with dementia brings high costs to society. In the UK, these costs are estimated to be $£ 26.3$ million, $£ 11.6$ million of which is contributed by unpaid carers. It is estimated over 600,000 family members provide unpaid care for people with dementia (Alzheimer's Society, 2012).

NHS Commissioning (2018) define a carer as; "someone who provides unpaid care for a family member, partner or friend who needs help due to their illness, frailty, disability or mental health problem and cannot cope without their support." Spousal caregivers often take on the role of primary caregiver (Monahan \& Hooker, 1995) which is increasingly challenging as the person with dementia (PwD) declines both cognitively and physically.

Many family carers feel it is their duty to care for their relative and do not therefore see their role as that of a carer. They often gain a sense of personal satisfaction in being able to provide care (Banerjee, 2014). In the current study, 'carer' refers to the relative of the PwD.

Family and informal carers provide direct assistance, emotional support and act as advocates to their relatives (Shanley, Russell, Middleton \& Simpson-Young 2011). However, healthcare providers often overlook carer needs (Alzheimer's Society, 2009). Caring for a PwD brings several health, psychosocial and practical challenges for the carer throughout the course of the disease. Carers face changing roles, an ongoing grieving process and the uncontrollable nature of dementia (Schoenmakers, Buntinx \& Delepeleire, 2010). The emotional and physical impact of caring for a relative with dementia has led to carers being described as 'invisible second patients' (Brodaty \& Donkin, 2009). Carers often experience high levels of depression, stress and physical illness (Argimon, Limon, Vila \& Cabezas, 2005). Carer distress is significantly under reported in this population (Neil \& Bowies, 2008). It is therefore vital that the needs of carers are understood and proactive interventions are provided.

\section{Needs of carers of relatives with dementia}

When examining the needs of family carers of a PwD, Pini, Ingleson, Megson, Clare, et al., (2017) critique existing research for focusing on care needs rather than the human needs of carers. They use a systematic review conducted by McCabe, You and Tatangelo (2016) to support this notion. The systematic review included twelve qualitative studies that reported on the self-perceived need of spouses or children of caregivers for people with dementia in community settings. Two themes emerged; caregiver needs related to the management of older people with dementia and caregivers' personal needs. It could be argued that caregivers' personal needs are 
human needs. However, as the review included qualitative studies, which reported on the self-perceived needs of carers, the findings presented are from the voice of carers. If care needs are a neglected area, it is possible that carers may dismiss them as being important when considering their own needs.

Given the demands placed on carers, it could be assumed that when a relative with dementia is admitted to hospital, carers may feel a sense of relief at having a period of respite from the ongoing caregiver stress. However, research findings have been to the contrary. Jurgens, Clissett, Gladman and Harwood (2012) conducted thirty-five qualitative interviews with relatives of confused older adults who had been admitted to a general hospital. The grounded theory study investigated why carers are dissatisfied with care. At the point of admission, carers were often emotionally and physically exhausted. Rather than the admission being a period of respite for carers, it was found to bring much disruption to their routine and travel to and from hospital was found to be an added stressor. The lack of information being provided to carers was identified as a factor in relationship breakdown between staff and relatives.

Wilkinson and McAndrew (2008) conducted an Interpretative Phenomenological Analysis to explore the perceived levels of involvement of individuals $(n=4)$ whose relative had been admitted to a mental health ward in the previous two years. Four main themes emerged from the data; powerlessness, feeling isolated, needing to be recognised and valued, and a desire for partnership. Given the small sample of participants, further study in the area with a larger sample would be of benefit. As stated, the sample were recruited from an adult mental health ward, however the findings are important in informing the current study.

There is currently no literature regarding what staff perceive the needs of carers to be when their relative is admitted to a dementia ward. It has been stated the assessment of carers needs is typically informal and undocumented which makes the needs of carers less clear and visible. Shanley, et al., (2011) believe those who care for relatives with dementia should have the opportunity to articulate their needs to researchers. Understanding the needs of carers from their perspectives will assist in the development of interventions to ensure carers needs are met (McCabe et al., 2016).

\section{Purpose and Aims}

Despite the growing prevalence of dementia along with increasing numbers of family carers, little is known about the specific needs of carers when their relative is admitted to a dementia ward. Providing insight into this area is essential. This insight would aim to improve the care and consideration that carers themselves receive.

This study aimed to develop an understanding of the needs of carers when a relative with dementia is admitted to a dementia ward, through developing a substantive theory grounded in the individual's perspectives.

The researchers were interested in the following questions:

- What do carers of an individual with dementia identify as their needs when their relative is admitted to a dementia ward?

- How do ward staff on a dementia ward perceive the needs of carers of individuals with dementia to be at the time when their relative is admitted to a dementia ward? 


\section{Method}

Grounded theory is a qualitative research method, developed by Glaser and Strauss in 1967. It is an inductive process, aiming to develop theory through continuous processes, tying the emerging theory closely with the data (Howitt, 2010). The purpose of grounded theory is to elicit a fresh understanding of patterns of relationships between social actors and how these interactions construct reality (Glaser and Strauss, 1967).

Constructivist grounded theory is underpinned by a social constructivist view of reality and acknowledges the subjectivity of data and the researcher's involvement with the construction and interpretation of data (Charmaz, 2014). The researcher's knowledge, decisions, philosophical position, background and use of method are acknowledged and shape the research process and findings. The researcher does not impose their own views and perceptions on the data and remains open to the emergence of theory. Being reflexive is imperative to researchers using grounded theory (Birks \& Mills, 2011).

\section{Research Design}

Semi-structured interviews were used as they allowed the researcher to modify questions in consideration of participant responses and investigate important areas (Smith, Flowers, \& Osborn, 1997). Subsequent interviews included questions devised from the analysis of the preceding interview, in line with the iterative process of grounded theory. Interviews took place at either the participants own home or within the National Health Service (NHS).

\section{Participants}

The recruiting ward was located in the North East of England covering a large geographical area in a large Mental Health Foundation Trust. Care is delivered by a multidisciplinary team on a mixed sex organic ward comprising sixteen patient beds. The function of the ward was predominantly assessment based, in which patients were admitted for a number of reasons including: risk (e.g. to the self, of placement breakdown, or to carers) and challenging behaviours. The remit of the ward was to assess the patient fully, leading to formulation and intervention. Given the variety of patient need, the length of stay could vary significantly from a few days to a number of weeks.

In total eleven participants participated in the study, comprising six staff and five carers. The six staff included one senior member of the nursing team, one staff nurse, one Health Care Assistant, two Community Psychiatric Nurses (who both had experience of the ward environment) and one Assistant Psychologist.

\section{Procedure}

Potential participants were informed of the study orally and via a Patient Information Sheet (PIS), which included information about the process of the study, confidentiality and data storage. Participants were informed that they could withdraw their consent up to four weeks after being interviewed. Participants agreeable in taking part in the study signed a consent form. No participants requested to withdraw from the study. The data obtained from the initial sampling was analysed and used to inform the 
qualities required of the next interview and purposive sampling was employed. Following completion of recruitment, validation interviews were completed with a subsample of participants to confirm the emerging theory.

All personal information was stored in line with the Data Protection Act (1998). Participants were informed that confidentiality would only be breached should information be disclosed which indicated risk to either themselves or others. At no point was the researcher required to breach confidentiality. The interviews were designed to be as sensitive as possible and the researcher monitored the wellbeing of participants verbally throughout the interviews.

Ethical approval for the study was obtained from the University Ethics Board, a full Research Ethics Committee Review and the Trust's Research and Development Department.

\section{Data Analysis}

Transcribing interviews is an integral part of the analytic process, providing the researcher with a close acquaintance with the data (Psathas \& Anderson, 1990). Each interview was audio recorded and transcribed verbatim by the researcher (JC). Data was analysed by a process of initial coding. This involves coding the data line by line, the researcher assesses what is happening in each line of the data and what theoretical ideas it suggests (Charmaz, 2014). Constant comparison is the process of critically checking aspects of the analysis against other aspects, with the aim to assess the extent the aspects relate to one another (Howitt, 2010) and is a fundamental part of grounded theory. Constant comparison continues until a grounded theory is fully integrated (Birks \& Mills, 2015).

Focussed coding then involves separating, sorting and synthesising large amounts of data (Charmaz, 2014). Thereby the researcher moved from smaller initial codes to integrating these into more focused codes, accounting for larger parts of the data. The researcher then used theoretical coding to "weave the fractured story back together". (Glaser, 1978).

\section{Results}

\section{Respondent validation}

The theory reached theoretical saturation after eleven interviews. To ensure rigour of the study and in line with resonance, the researcher invited all participants to comment on and validate the emerging theory. Four participants participated and provided feedback. The four participants felt the model fit with what they had discussed during their interviews:

\section{C2: "I'm quite impressed with that."}

C2: "Being informed about what's going on is really important, and I think this sort of inclusiveness is really important to people. Yeah, it's good." 


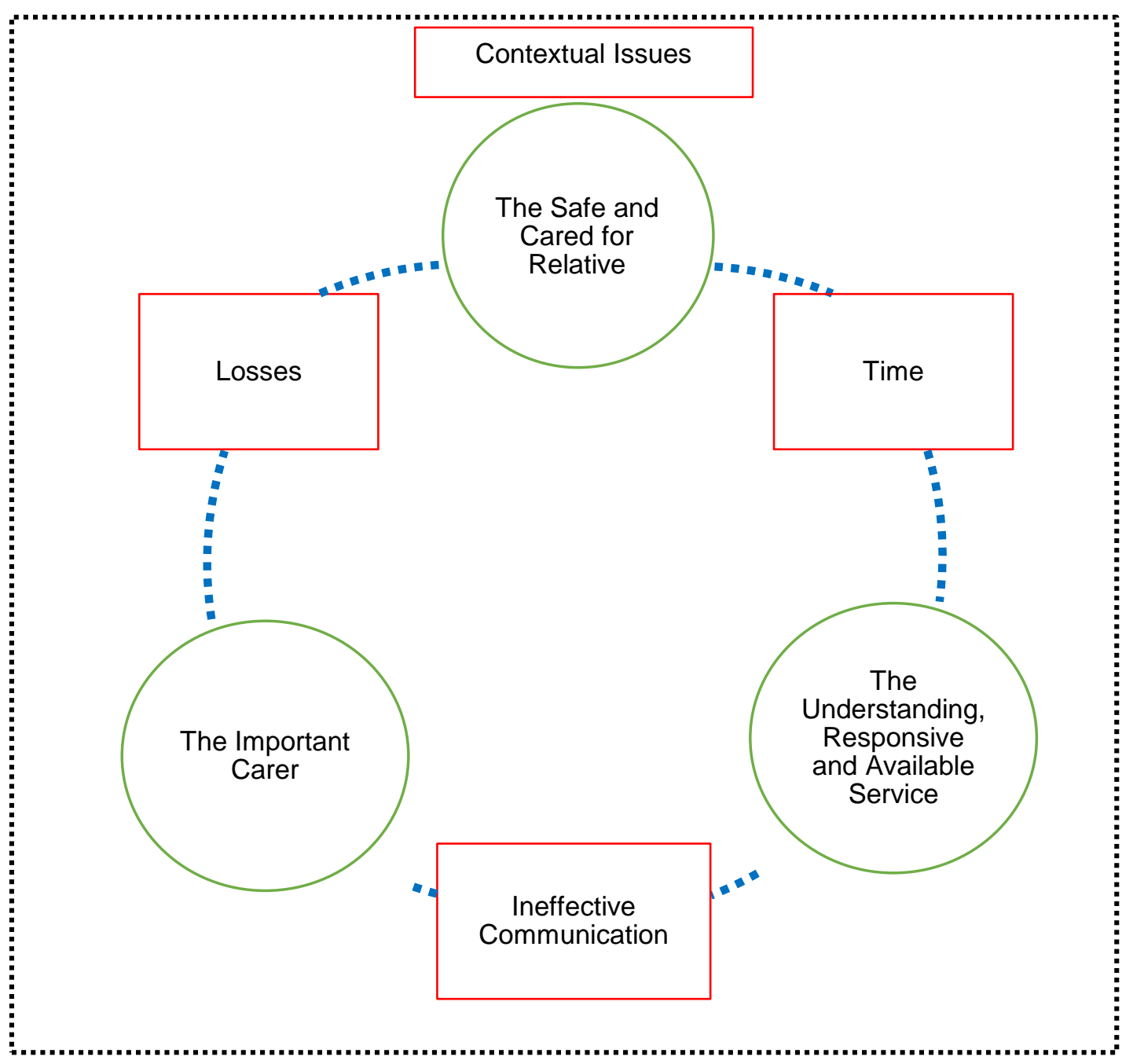

Figure 1: The End Theory

Figure 1 provides a diagrammatic representation of understanding the needs of carers when a relative with dementia is admitted to a dementia ward. There were three categories of needs identified for carers. Highlighted in green circles these are:, 'The Safe and Cared for Relative', 'The Important Carer' and 'The Understanding, Responsive and Available Service'. Three barriers to care identified were 'Losses', 'Time' and 'Ineffective Communication' and are identified in red boxes. A number of subordinate themes, which will be described below, underpinned each superordinate theme. Where examples of quotes are used, $\mathrm{S}$ will denote quotes provided by a staff participant and $\mathrm{C}$ will denote a quote provided by a carer participant. 


\section{The Safe and Cared for Relative}

Alongside the importance of involvement, carers also have a need for 'The Safe and Cared for Relative'. Carers and staff noted that the basic needs of the patient are vital. Two subordinate themes were identified: 'Safe and Cared For' and 'Positive Interactions with Staff'.

Safe and Cared For

Carers need to view the ward as a safe environment where the basic needs of their relative are met. This is a time carers are relinquishing their care role to some extent and understandably want to feel their relative is safe and cared for:

C3: "Yeah... I always felt that he was safe and I always felt they didn't judge him when he was challenging with them."

It was believed by staff that carers needed to be able to see their relative's basic needs were being met. These basic needs included that they were clean and fed with clear observable markers:

S1: "Look tidy. Erm, that's a big thing for people because if they're not that then I think that makes them think they're not being cared for, who's looking after my relative?"

Positive Interactions with Staff

Carers gained reassurance from observing the positive interactions between their relative and ward staff. There was a sense of joy and happiness in being able to see the relationships that staff developed with patients:

C1: "I thought they were fantastic with him. (Laughs). It was lovely. They were walking down from the door to the erm.... Eye clinic, with their hands, holding their hands up and he was trotting between them, and do you know, it was lovely to watch them"

It was important for carers to be able to see that they had been heard when discussing strategies they themselves have used in managing their relative at home. This was demonstrated through staff taking on this advice, using the same techniques and carers observing this when visiting:

C4: "And if you can sit with him with your arm like that, then he, you know when he's laid down then he seems to relax a bit, and they've seen me doing it and now they do it."

\section{The Important Carer}

With regards 'The Important Carer', carers noted a shift in role once their relative is admitted to a dementia ward. This is a difficult time and a time in which they are required to hand over care. To remain involved, they must be well informed throughout their relative's admission and have a voice, which is heard. This requires staff to respond appropriately. Overall, there is a need for the carer and their important role to 
be recognised. The subordinate themes for the 'Important Carer' were 'Fully Informed' and 'Maintaining Inclusion'.

Fully Informed

Many carers have provided care for their relative whilst at home, thus when their relative is admitted to a ward, their role changes. They are not with their relative for the long periods of time they are used to, which brings an unknown. Understandably, carers are concerned for their relative and being informed about the admission is a priority.

S6: "I think they [relative] might have their own need's but their main need $90 \%$ of the time is "what's happening with my loved one..."

C4: "You just need reassurance that they're doing their best ...things like that, that's all you need really, to know that they're ok."

Maintaining Inclusion

One factor important in being able to meet this need is ensuring the inclusion of carers. Psychological formulation is an integral part of an individual's care whilst under the care of mental health services. Ward staff clearly recognised the need for formulation, and the importance of including carers in such meetings.

S6: "I always to try to say, you're the expert on this person. You've known them, you're their husband or wife whose been married to them for 50 years... you know them, you can tell us all about them."

In turn, carers spoke highly about their involvement in the formulation meetings too:

C4: "Yes, it's helpful to talk about him, you know get across what sort of person he was and things like that."

\section{The Understanding, Responsive and Available Service}

Carers also have a need for 'The Understanding, Responsive and Available Service'. Carers often put the needs of their relative before their own, and therefore require a proactive approach from staff to allow them to recognise their own needs and give permission for self-care. There are three subordinate themes identified here: 'Approachable Staff', 'Empathic Stance' and 'Responding to Carer Needs'.

\section{Approachable Staff}

For any needs of the carer to be met, staff need firstly to be approachable. Being approachable ensures carers feel able to ask about their relative, obtain information and developing a safe and trusting relationship with ward staff:

C4: "They talk to you, not above you. You know like years ago I think doctors talked past you if you know what I mean?"

\section{Empathic Stance}


Throughout the interviews, carer participants articulated their difficult experiences during the more challenging times since their relative received a dementia diagnosis. Despite their relative being in hospital, they continue to find life stressful and difficult. Carers need staff to be understanding of, and validate these experiences.

C3: "Bringing dad in, er, it was distressing for everybody and they did their best to try and protect me from that."

Responding to Carer Needs

Carers may not be assertive when it comes to their own needs, therefore there is requirement for staff to be vigilant and aware of carers who may be struggling and be proactive in approaching them:

C4: "I always think, I can do it, I'm alright, I can do it. I'm not very good for asking for help. People have to tell me you have to do it."

S6: "You don't, your loved one is here being cared for by professionals who are

here to do that. If you need a break so that you can then come and look after them and be the carer for them then you take that break. It's important, especially whilst you've got this opportunity when this person is in hospital to be able to recharge your batteries. Erm, I do think some people need permission, for that."

The ward has introduced a member of staff whose role is primarily carer engagement. This role was spoken of highly by both carers and staff. The main reason for this was that this role could offer time:

S1: "That's another, but that's impacted on the carers massively as well, having someone who's actually ringing them, engaging them, giving them a bit more of a voice. The last year I think since she's started, those links with the families have got better."

\section{Time}

The first barrier to carers needs being left unmet, was that of time. There were two subordinate themes within this category, that of 'Time Available for Carers' 'Time for the Team'.

Time Available for Carers

Time is invaluable, however, sometimes there is not enough time to be able to respond to carers effectively, spend time together as a team and importantly time for community staff to maintain and develop relationships with carers. 
S2: 'Sometimes, again, and because everybody's busy and short staffed they don't even get enough, I don't think, would you like a drink? Would you like something to eat? You know just those practical things that make someone feel comfortable. We do it, not saying we don't do it, but we don't do it immediately because if we've been busy, or we don't ask them enough."

Time for the Team

In addition, ward staff often had limited opportunities to come together as a whole team. This affected the communication between the team and even staff developing working relationships with each other.

S2: 'We've got a big staff group, you might not see some of the staff that you're working with, you might not see them for a couple of months, so I don't know, how you would, how that would be able to be addressed...it's just trying to do it..."

\section{Ineffective Communication}

Ineffective communication was identified as a barrier with two subordinate themes, 'Ineffective Communication with Carers' and 'The use of language'.

\section{Ineffective Communication with Carers}

This subordinate theme centred on carers not being fully informed, discrepancies in updates and progress and miscommunication of important information. This ultimately leads to a disruption in the relationship with staff and questions regarding what is happening on a day-to-day basis with their relative.

C2: "I wanted to know, you know, because when went to a safeguarding meeting, all of a sudden this CPN said we've had to sedate him. And when it turns out, he'd had ... Lorazepam on one day.. a low dose. Cos at the meeting I was quite cross and I used the term chemical handcuffs..."

\section{The Use of Language}

The way carers are communicated with can also act as a barrier. One such example is use of the term carer. It can act as a barrier to those who do not consider themselves a carer and would affect the likelihood of taking up support offered to "carers'.

C3: "I'm....ambivalent about it. It's not a word I like because I don't consider myself his carer. I'm his daughter."

\section{Losses}

Losses were an additional barrier noted with carers and individuals with dementia experiencing multiple losses throughout the progression of the illness. It can be an extremely distressing and challenging time. Carers may be seen to experience denial as they navigate the ongoing loss of their relative and the progression of dementia.

S2: "Some relatives and carers come here every day and they'll stay for a long time or they'll come for at least three, four times a week. And you get other patients who very rarely see a carer or a relative, but that's sometimes about denial... I've had carers say I just can't face seeing that person the way they are, it's too painful for them 
to come, so they'll only come on occasions, make sure they're alright and then go, they don't stay very long."

Staff also experienced feelings of loss, emphasising the importance staff place on the relationships developed during an individual's admission to a dementia ward. The power of such relationships and the impact this ending has on staff should not be underestimated.

S1: "Obviously having to care for somebody who is dying is, you know, and being there at the end of their life is a privilege, but it also can be quite upsetting for some people."

\section{The Wider Context}

The blue circle, which connects the three categories, represents the connection between the PwD, carer and staff, with the PwD at the centre. This is demonstrated using a hatched line to highlight the possibility of connections becoming fractured when barriers to meeting carers needs are not overcome.

Finally, the model is framed with an outer line, a representation that the model accounts for one specific ward. 'Contextual Issues' brings additional factors which need to be acknowledged and considered when meeting the needs of carers. Shift working for example is an inevitable part of working in healthcare, in particularly inpatient wards. However, the shift patterns can indirectly affect the carer patients receive:

S2: "The biggest problem with that and what stops that, what makes it ineffective is we work 12 hour shifts. We might be in for three then we might be off for four. Sometimes you might be off for six depending on how your shifts work. So you come back and you've missed an awful lot and with the best will in the world, no one if going to remember everything."

S3: "So, you could have had a very good relationship going with a relative and like you said they could be gone when you come back on shift couldn't they? And you wouldn't have been there to support them."

\section{Discussion}

The aim of this study was to capture the needs of carers when their relative is admitted to a dementia ward and how staff perceive such needs. Given the reported impact caring has on individuals looking after a relative with dementia, it is imperative to ensure services are actively and appropriately meeting carers needs. Developing a theory grounded in the voice of carers and staff living through such experiences provided an opportunity to develop a meaningful model to understand these needs. The data was used to develop a comprehensive model containing saturated categories accounting for the needs of carers when a PwD is admitted to a dementia ward. 
The 'Safe and Cared For relative' is a fundamental aspect of the grounded theory. In most instances, this was the primary concern for carers, that their relative was cared for. Carers judged this through the physical appearance of their relative and interactions with staff. Staff also perceived this would be an important need for the carer, which aligned with their own clinical beliefs regarding care. Staff believed carers would judge the quality of care based on the physical appearance of their relative. This is in line with the findings of Jurgens et al., (2012) who found carers to judge the quality of care in terms of food, hydration, maintaining safety, displaying warmth and using appropriate approaches to care. The need to observe very basic needs being met draws parallels with Maslow's Hierarchy of Needs (Maslow, 1970). Needs lower in the hierarchy (e.g. physiological needs and safety) must be satisfied prior to the higher needs being met (Lauri, Lepisto and Kappeli, 1997).

The need for safety expands beyond physical safety. It can also relate to safety in terms of Attachment Theory (Bowlby, 1969). With adult attachments, primary attachment figures are typically a friend or partner (Hazan \& Shaver, 1987), whilst parental attachments remain. Needs should be reliably and sensitively met for individuals to be able to safely explore their world. It could be argued that the needs of carers should be sensitively met by ward staff to ensure they feel safe leaving their relative in the care of individuals whom they are likely to have had no or little contact with previously. The ward becomes not only a physical safe base but also a secure base for carers. The current study did not assess carer's attachment type, however it would be an interesting avenue to explore. Within the 'Understanding and Responsive Service' theme, it was recognised that carers can often find it difficult to consider their own needs. Staff were aware of the importance of their own roles to recognise these needs within the carer and at times provide them with permission to care for themselves. As a result, developing the relationships between the staff members and the carers are paramount. The End Theory (see Figure 1.) identifies staff should be ensuring a safe base is established for both the carer and their relative.

Positive interactions with members of staff and the PwD is also imperative. Carers spoke with real fondness observing the developing relationships. The interactions were also a way of carers observing that their information and advice had been listened to and was being used effectively. This perhaps gave an example of the triad relationship being most effective and reflective of the collaborative care, similar to the Triangle of Care (Worthington, Rooney and Hannan, 2013). It also reinforced the need for carers to be viewed as an 'expert', with validating that their contributions are important. It seems therefore, that positive relationships between staff, PwD and carers are key to ensuring quality care. Similar findings have been noted in the wider literature between PwD and staff in care homes. In a cross sectional study using questionnaires to determine the attidudes of staff towards residents with dementia in a nursing home, Gerritsen, van Beek and Woods (2018) found that staff who had more positive attitudes and relationships with their residents experienced greater resident wellbeing.

In terms of barriers, 'time' contributed to staff finding it difficult to meet the needs of carers, which in turn led to 'ineffective communication'. Whilst it was acknowledged carers were important, ultimately clinical tasks would take priority. This affected staff being able to meet carers' needs. Likewise, Giacco, Dirik, Kaselionyte and Priebe (2017), reported staff stated organisational and systemic issues acted as barriers in 
reducing the time available to engage with carers. 'Loss' was a further barrier, particularly in which carers spoke of the ongoing difficulties in accepting the situation of their relatives' ongoing progression and decline. Carers of a PwD have been said to experience triple grief as they cope with and manage the behaviours displayed, confront the possible admission of their relative to a permanent care facility and grieve for the death of their relative or partner (Ott, Kelber and Blaylock, 2010).

\section{Implications for Clinical Practice}

Given the end theory proposes a model to understand the needs of carers when their relative with dementia is admitted to an organic ward, there are implications for clinical practice and considerations of how to overcome barriers.

As discussed, it is important the ward be viewed as a safe base for carers. Fostering positive relationships with carers and their relative, as well as listening to carers and ensuring they are fully informed, all contribute to the development of a secure base. Availability and responsiveness are key features of a secure base (Bowlby, 1969) therefore, they should be aimed to be achieved by all staff.

Time was identified as a barrier to carers needs not being met, and impacts on availability and responsiveness. However, releasing time does not have to be intensive. Being able to respond sensitively to carers needs may require some consideration. The current study showed how the service had introduced a new member of staff dedicated to carer engagement. This in itself was leading to positive feedback, and reviewing the utility and effectiveness of the role would be helpful to consider the benefits of carers needs being met more effectively. The model stipulates a need for carers to be both viewed as an expert but also have their emotional needs met. This creates an interesting dynamic which requires some negotiation.

The role of a clinical psychologist on the inpatient units could also be key from working with staff to develop systemic formulation of the PwD and the surrounding system; to training staff in areas of attachment theory and the importance of relationships; as well as supervising ward staff in their delivery of care to carers and PwD. The sensitive area of loss that has been a theme throughout the study, is also important to be considered particularly in working collaboratively with staff and carers in relation to the impact of grief and loss within dementia.

\section{Limitations of the Study}

A primary limitation of a constructivist grounded theory approach is that the findings cannot be applied to other individual's experiences in differing situations and contexts. This therefore limits the generalisability of the results. However, the developed theory may have relevance in other settings, for example, contributing to the understanding of needs of a carer when a relative is admitted to an acute hospital for medical needs and to some extent the needs of carers when their relatives are admitted to mental health hospitals.

This study unfortunately had a limited sample with regards to diversity. Four of the five carer participants were female. It would, therefore, have contributed further to the usefulness of the theory had more male carers had been included. There was also a lack of diversity amongst the gender of staff, all those recruited were female. Positively 
staff from a range of disciplines participated with a range of experience. This provided interesting insights and strengthened the data. Each participant identified their ethnicity as White British, which also limits the generalisability of the findings.

\section{Conclusion}

This study provided a constructivist grounded theory explaining the needs of carers when a relative with dementia is admitted to a dementia ward. There are three main components of needs relating to the carers, relative and staff. The identified needs included 'The Important Carer' 'The Safe and Cared for Relative' and 'The Understanding, Responsive and Available Service'. The End Theory also highlighted barriers to these needs being met, these are 'Loss', 'Time' and 'Ineffective Communication'. The findings highlighted that carers find it difficult to acknowledge and consider their own needs, almost passing over their needs to focus on those of their relative. Thereby this requires a proactive approach from staff to meet their needs by recognising when carers may be struggling, providing a safe space on the ward, acknowledging the carer as important and most importantly fostering good relationship with carers and their relative.

\section{References}

Alzheimer's Society. (2012). Dementia 2012: A national challenge. Retrieved from https://www.alzheimers.org.uk/sites/default/files/migrate/downloads/alzheimers_soci ety_dementia_2012-_full_report.pdf

Alzheimer's Society (2009) Counting the Cost: Caring for people with Dementia on Hospital Wards. London: Alzheimer's Society. Accessed at: https://www.alzheimers.org.uk/sites/default/files/2018-

\section{5/Counting the cost report.pdf}

(accessed 30.07.19)

Argimon, J. M., Limon, E., Vila, J., \& Cabezas, C. (2005). Health related quality of life of caregivers as a predictor of nursing home placement of patients with dementia. Alzheimer Disease \& Associated Disorders, 19(1), 41-44.

Bang, J., Spina, S., \& Miller, B. L. (2015). Frontotemporal dementia. The Lancet, 386(10004), 1672-1682.

Birks, M., \& Mills, J. (2011). Grounded Theory: A Practical Guide. London, UK: Sage Publications Ltd.

Birks, M. \& Mills, J. (2015). Grounded Theory: A Practical Guide (Third Edition). London, UK: Sage

Bowlby, J. (1969). Attachment and loss. Vol: 1 Attachment. New York: Basic Books.

Brodaty, H., \& Donkin, M. (2009). Family caregivers of people with dementia. Dialogues in clinical neuroscience, 11(2), 217

Charmaz, K. (2014). Constructing grounded theory. London, UK: Sage Publications. 
Data Protection Act. (1998). Accessed at: www. legislation.gov.uk (accessed 30.07.19)

Giacco, D., Dirik, A., Kaselionyte, J., \& Priebe, S. (2017). How to make carer involvement in mental health inpatient units happen: a focus group study with patients, carers and clinicians. BMC psychiatry, 17(1), 101.

Gerritsen, D. L., van Beek, A. P. A. \& Woods, R. T. (2018). Relationship of care staff attitudes with social wellbeing and challenging behaviour of nursing home residents with dementia: a cross sectional study. Aging and Mental Health. 23, 1517-1523.

Glaser, B., \& Strauss, A. (1967). Grounded theory: The discovery of grounded theory. Sociology the journal of the British sociological association, 12, 27-49.

Glaser, B. (1978). Theoretical sensitivity: Advances in the methodology of grounded theory. Mill Valley: Sociology Press.

Hazan, C., \& Shaver, P. (1987). Romantic love conceptualized as an attachment process. Journal of personality and social psychology, 52(3), 511.

Howitt, D. (2010). Introduction to qualitative methods in psychology. Essex: Pearson.

Jurgens, F. J., Clissett, P., Gladman, J. R., \& Harwood, R. H. (2012). Why are family carers of people with dementia dissatisfied with general hospital care? A qualitative study. BMC geriatrics, 12(1), 57.

Lauri, S., Lepisto, M., \& Kappeli, S. (1997). Patient's needs in hospital: nurse's and patients views. Journal of Advanced Nursing, 25, 339-346.

Maslow, A. (1970). Motivation and Personality. New York: Harper \& Row.

McCabe, M., You, E., \& Tatangelo, G. (2016). Hearing their voice: A systematic review of dementia family caregivers' needs. The Gerontologist, 56(5), 70-88.

Monahan, D. J., \& Hooker, K. (1995). Health of spouse caregivers of dementia patients: The role of personality and social support. Social work, 40(3), 305-314.

Neil, W., \& Bowies, P. (2008). Carer burden in dementia-assessing the impact of behavioural and psychological symptoms via self-report questionnaire. International Journal of Geriatric Psychiatry: A journal of the psychiatry of late life and allied sciences, 23(1), 60-64.

NHS Commissioning (2018). Who is considered a carer? Accessed at: https://www.england.nhs.uk/commissioning/comm-carers/carers/ 30.07.19)

(accessed

Ott, C. H., Kelber, S. T., \& Blaylock, M. (2010). "Easing the way" for spouse caregivers of individuals with dementia: A pilot feasibility study of a grief intervention. Research in Gerontological Nursing, 3(2), 89-99. 
Pini, S., Ingleson, E., Megson, M., Clare, L., Wright, P., \& Oyebode, J. R. (2017). A needs-led framework for understanding the impact of caring for a family member with dementia. The Gerontologist, 58(2), 68-77.

Prince, M., Knapp, M., Guerchet, M., McCrone, P., Prina, M., Comas-Herrera, A., Wittenberg, R., \& Rehill, A. (2014). Dementia UK: -overview. Available at: http://eprints.Ise.ac.uk/59437/1/Dementia UK Second edition - Overview.pdf (accessed 30.07.19)

Prince, M., Wimo, A., Guerchet, M., Ali, G. C., Wu, Y. T., \& Prina, M. (2015). World Alzheimer Report 2015- The Global Impact of Dementia: An analysis of prevalence, incidence, cost and trends. Available at: https://www.alz.co.uk/research/WorldAlzheimerReport2015.pdfhttps://www.alz.co.uk/ research/WorldAlzheimerReport2015.pdf (accessed 30.07.19)

Psathas, G., \& Anderson, T. (1990). The practices of transcription in conversation analysis. Semiotica, 78(1-2), 75-100.

Schoenmakers, B., Buntinx, F., \& Delepeleire, J. (2010). Factors determining the impact of care-giving on caregivers of elderly patients with dementia. A systematic literature review. Maturitas, 66(2), 191-200.

Shanley C., Russell C., Middleton H. \& Simpson-Young V. (2011) Living through endstage dementia: the experiences and expressed needs of family carers. Dementia 10(3), 325-340.

Smith, J. A., Flowers, P., \& Osborn, M. (1997). Interpretative phenomenological analysis and the psychology of health and illness. Material discourses of health and illness, 6891.Wilkinson, C., \& McAndrew, S. (2008). 'I'm not an outsider, I'm his mother!' A phenomenological enquiry into carer experiences of exclusion from acute psychiatric settings. International Journal of Mental Health Nursing, 17(6), 392-401.

Worthington, A., Rooney, P., \& Hannan, R. (2013). The triangle of care-carers included: a guide to best practice in mental health Care in England. London: Carers Trust.

\section{Acknowledgements}

We would like to thank $\mathrm{Dr}$ Graeme Flaherty-Jones for his guidance and support through the research process.

Most importantly, we would like to thank the participants of the study. A special thank you to the carers for their open and honest accounts during a difficult time, in the hope of being able to jointly develop something of value to support other carers in the same situation.

This piece of research was completed in fulfilment of the award of Doctor of Clinical Psychology at Teesside University and no external funding was received for the study. 